\title{
Study on Communication Technology among the Electronic Systems
}

\author{
Xiao Hai-liu \\ NanChang Institute of Science \& Technology
}

\begin{abstract}
The world today is the world with science and technology as its dominance; the innovation of science and technology has promoted the development of social productive forces, has upgraded the degree of social civilization and civilized degree, and changes people's way of life; and especially the development of electronic communication technology has greatly expanded the living space of people and broken the time and space limits between interpersonal communication, has optimized the country industrial structure and strengthen our national comprehensive strength in the international market. In the tide of development of electronic communication technology, it is worthy for each communication technology staff to think deeply that how to draw on the advantages and avoid the disadvantages, to reform and innovate and to occupy more share in the international market and to promote the sustainable development of national economic. In following essay, it will put forward the corresponding reform methods on how to innovate electronic system communication technology combining with the present situation that technology developing is not the corn for electronic communication technology and Chinese national condition, and if there any shortage or lack of place, please peer criticism.
\end{abstract}

Keywords-Electronic system; Wireless mobile communication; Man-machine interface; Function module

\section{INTRODUCTION}

Since Baer invented the telephone in 1876, and after experienced more than one century development, the telephone communication service has entered the household, and has become the indispensable important tool for national economic construction and for social life and people exchange information. In last twenty years, the telephone technology and business has encountered a great change -- the location of the communication is shifted to the mobile mode from fixed mode. It has experienced the first generation of mobile communication of simulation and the second generation mobile communications of data, and now it is in the third generation of high-speed data services, and in the future, it will enter the fourth generation and the fifth generation of mobile communication technology era.

Mobile communication terminal products is complex electronic system, including the most basic software and hardware, hardware design includes baseband circuit and RF circuit and structure, while the software design is more complex and includes the underlying driver design, application software design and user interface design and etc., and these are the most complex parts, and in addition the same for the software testing design; after the finish of designation, the work of testing is then necessary, the test is the assurance of quality and the design without testing can not be seen as a perfect product although the quality is designed, moreover, production also needs testing which is for each of the products. Therefore, the arrangement and the professional involved in mobile communication terminal products are wide, this paper mainly studies on the basic knowledge structure of the hardware, introduces the function of the basic functional modules and the function needs to be finished, and describes the methods and techniques of each of the functions by using a lot of actual circuits. It is different for the functions of each of the products, but the basic design idea and method is the same, and the paper is to make research on design basis and only to provide references but can not be complete or give mature consideration to all aspects of a question.

This paper will introduce the developing history of the mobile communication and also the differences of each generations of it, and the future developing third generation of mobile communication is the key point. In 
addition, this essay will introduce the man--machine interface of the mobile communication terminate products design which includes display function, input function and charging function and etc., and also describe the design methods by using specific circuit.

\section{MOBILE COMMUNICATION TERMINAL SYSTEM MODULE INTERFACE}

Analog voice input is mainly a microphone, voice output mainly includes receivers, loudspeakers and headphones, the three outputs mentioned here are almost the same and are used in different occasions, and the power output also have different correspondingly, while the effective signal frequency band are also different. The following will first introduce the basic knowledge of the speaker, microphone and receiver, and then introduce the function interface.

Microphones used in mobile communication terminal products mainly include capacitor type microphone and the silicon microphone as the representative of the America Knowles Electronic; and the capacitor type microphone is the one which used more widely because of its low price. As for loudspeakers, buzzer which can only speak out some simple synthetic voice was used in early mobile communication terminal products, it was not able to achieve the quality requirement as the products in today, and the loudspeaker is used instead in late years. Recently, a kind of loudspeaker with piezoelectric ceramics is used but not popular.

If set the surface charge quantity is $\mathrm{Q}$, the capacitance of the electrode plate is $\mathrm{C}$, the distance of the electrode plate is $\mathrm{d}$, the electrode area is $\mathrm{S}$, and the electric charge $\mathrm{Q}$ is a certain value, then a formula is firstly imported:

\section{$\mathrm{C}=\mathrm{Q} / \mathrm{U}$}

On the other side of the capacitor is a thin diaphragm, which vibrates when subjected to vibration or air flow, and this vibration changes the distance $\mathrm{d}$ between the two electrodes, and then another formula is introduced:
The amount of FET working condition is the gate source voltage U. From the above two formula then is easy to export:

$$
U=Q 4 \pi k d /(\varepsilon S)
$$

\section{RF DESIGN OF MOBILE COMMUNICATION TERMINAL}

RF impedance matching is not only the most basic work in design but also very important work, the impedance is generally drawn from the Smith Impedance Circle which has been proved by practices to be the basic tool for calculating the impedance of the transmission line. The paper takes the mapping of the reflection coefficient, impedance and admittance as an example, and designs a matching network with frequency of $60 \mathrm{MHz}$ by using mapping method to make the introduction.

The intensity of the load reflection signal depends on the mismatch between the signal source impedance and the load impedance. The expression of reflection coefficient is defined as:

$$
\begin{gathered}
\Gamma_{L}=\frac{V_{\text {ref }}}{V_{\text {ine }}}=\frac{Z_{L}-Z_{0}}{Z_{L}+Z_{0}}=\Gamma_{t}+j * \Gamma_{1} \\
Z=Z_{L} / Z_{0}=(R+j X) Z_{0}=r+j X
\end{gathered}
$$

Because the impedance is plural and the reflection coefficient is plural too, a parameter that is cured and often used in the application can be set in order to reduce the number of unknown parameters. Here zo (characteristic impedance) is usually a constant and real number, and the standard value which is commonly used, such as $50 \Omega, 75 \Omega, 100 \Omega$ and $600 \Omega$. So then, people can definite Normalized load impedance:

$$
z=Z_{L} / Z_{0}=(R+j X) Z_{0}=r+j X
$$

In accordingly, the reflection coefficient formula is rewritten to be:

$$
\begin{gathered}
C=\varepsilon S /(4 \pi k d) \\
\Gamma_{L}=\Gamma_{L}+j * \Gamma_{i}=\frac{Z_{L}-Z_{0}}{Z_{L}+Z_{0}}=\frac{\left(Z_{L}-Z_{0}\right) * Z_{0}}{\left(Z_{L}+Z_{0}\right) * Z_{0}}=\frac{Z-1}{Z+1}=\frac{r+j * X-1}{r+j * x+1}
\end{gathered}
$$


From the formula above, people can see the direct relationship between load impedance and reflection coefficient. However, this relation formula is a plural, and so it is not practical. People can use the Smith Impedance Circle as the graphic representation for above equation. In order to set the circle, the equation needs to be rearranged to suit a standard geometric figure (such as a circle or ray).

$$
z=r+j X=\frac{1+\Gamma_{L}}{1-\mathrm{T}_{L}}=\frac{1+\Gamma_{r}+j \Gamma_{i}}{1-\Gamma_{r}-j \Gamma_{i}}
$$

\section{ESTABLISH AND IMPROVE THE INCENTIVE AND}

\section{RESTR AINT IN THE FIELD OF ELECTRONIC}

\section{COMMUNICATION}

The first key for further improvement and development of electronic system communication technology is to establish and improve Industry field personnel incentive and restraint mechanism. The corn element is not the technique itself but the person and the mechanism for any one of the industry to become bigger and stronger and for any technology to be promoted and applies. Therefore, the primary premise of the development of electronic communication technology is to establish and improve the incentive and restraint mechanism, to enhance human resource management level, to vigorously develop high quality communication technology talents and to accelerate the pace of technical personnel in the field of communication. Moreover, it needs to pay high attention on personal education and training of communication technology among the electronic system to upgrade their enthusiasm and interest on drawing the new knowledge actively, constantly stimulate the innovative potential of the technical personnel, and expand the innovative thinking space of the technical personnel. It needs to vigorously implement the modern human resources management strategy to optimize staffing, and to hire new employees full of vigor and vitality and with new active thinking. It is too necessary to introduce market competition mechanism into the field of electronic communication technology, to strengthen the support on the development of corn technology, and to put a lot of human resources to enhance the sense of competition, cooperation and innovation awareness among employees, and to provide talent support for the development and strengthen of the electronic system communication technology is encouraged.

\section{V.CONCLUSION}

At present, it has experienced the first generation of mobile communication of simulation and the second generation mobile communications of data, and now it is in the third generation of high-speed data services, and in the future, it will enter the fourth generation and the fifth generation of mobile communication technology era.

In this paper, the development history of the mobile communication products is introduced, in addition, the most basic and the most common interface circuit and some common sense such as structural man-machine interface and functional module interface are also referred, and the basis and basic structural of Radio Frequency is too presented.

In summary, the communication technology between electronic systems has an inseparable relationship with our national industrial structure adjustment and the truth that the market competition is put as the focus in the international electronic communication technology. It is the duty for every staffs in field of electronic system communication technology that to pay high attention on its practical significance of electronic system communication technology development and to analyze the reform strategies for enhancing a further development, creation and strengthen of electronic system communication technology. In order to get a foothold and have a considerable development in the international market with increasingly fierce competition, people must make efforts from several aspects below: promoting the innovation and application of the basic and the core technology, enhancing the support on the basic and the core technology, establishing and improving the incentive and restraint mechanism in the field of electronic communication to culture communication technology talents with high quality, protecting intellectual property rights, actively promoting the construction of standardization system, scaly developing the patent technology and breaking the international standards of competition. 


\section{REFERENCES}

[1]Farin G, Farin G. Curves and surfaces for computer aided geometric design - a practical guide (3. ed.).[J]. Academic Press Inc Boston Ma, 1993.

[2] Wozencraft J M, Jacobs I M. Principles of Communication Engineering[J]. P.andersen \& L.k.guerrero Handbook of Communication \& Emotion Research Theory Applications \& Contexts, 1965.

[3] Ghavami, M. "Ultra Wideband Signals and Systems in Communication Engineering." Microwave Journal 3.1(2007):46.

[4] Mutagi, R. N. "'Pseudo Noise Sequences for Engineers", Electronics and Communication Engineering Journal, UK, Vol.8, No.2, April 1996." Electronics \& Communications Engineering Journal vol.8(1996).

[5] Authors U. Department of Electronics and Communication Engineering,[J]. International Journal of Engineering Science \& Technology, 2010, 107(4):379-396.

[6] Das, Sanjib, L. N. Sharma, and A. K. Gogoi. "Remote Communication Engineering Experiments Through Internet." International Journal of Online Engineering (2006).
[7] Das, Sanjib, L. N. Sharma, and A. K. Gogoi. "Remote Communication Engineering Experiments Through Internet." International Journal of Online Engineering (2006).

[8] Chen, Jian Jun. "The Experiment of Teaching for Communication Engineering." Modern Educational Technology (2012).

[9] Zhang, Jie, et al. "Exploration of Communication Engineering Practical Teaching based on Engineering Project Model." China Educational Technology \& Equipment (2013).

[10] Messerschmitt, David G., and I. S. Morrison. "Design of Interstellar Digital Communication Links: Some Insights from Communication Engineering." Acta Astronautica 78.5(2011):80-89.

[11] Ghavami, M. (2007). Ultra wideband signals and systems in communication engineering. Microwave Journal, 3(1), 46.

[12] Natarajan, A., Kalghatgi, A. T., Bhat, B. M., \& Satyam, M. (2001). Devices laboratory, department of electrical communication engineering, indian institute of science, bangalore-560012, india. Journal of Applied Physics, 90(12), 6434-6439. 